\title{
Los derechos privados constituidos sobre sepulturas. Reflexiones desde su problemática actual
}

Erick Ortega García ${ }^{1}$ Universidad de Camagüey

Revista Derechos en Acción ISSN 2525-1678/ e-ISSN 2525-1686

Año 4/No 12 Invierno 2019 (21 junio a 20 septiembre), 830-847

DOl: https://doi.org/10.24215/25251678e326

ORCID: https://orcid.org/0000-0002-6723-9716

\section{Introducción a la problemática actual en el reconocimiento de derechos sobre bienes cementeriales}

La concepción de los cementerios públicos, desde la perspectiva propia del Derecho, posee actualmente una destacada relevancia social y jurídica. Sobre todo cementerio, tanto los públicos como los privados, concurren potestades públicas, y potestades o derechos de los sujetos particulares que son usuarios del servicio de cementerio ${ }^{2}$. Parte de sus contradicciones normativas, que generan lagunas en los ordenamientos, viene dado desde la evolución histórica de los camposantos. Su nacimiento junto al hombre disponiendo sitios para inhumar los restos humanos, en consonancia con sus creencias religiosas, produjo un retardo en su evaluación como sujeto de derechos.

Todo ello ha generado que una de las principales dificultades a las que se enfrentan los operadores jurídicos al tratar las cuestiones que afectan a cementerios, es la complejidad y

\footnotetext{
1 El autor es Licenciado en Derecho por la Facultad de Derecho de la Universidad de Camagüey.

2 Rodríguez Blanco, Miguel, Régimen Jurídico de cementerios y sepulturas, Granada, Comares S. L., 2015, pp. 71-85.
} 
dispersión del régimen jurídico de cementerios, de las fuentes $^{3}$. De esta forma, surgen arbitrariedades que perjudican los derechos de los administrados, y que pueden generar responsabilidad de la administración por ejecución de actos absoluta o relativamente nulos. Esta situación exige una labor de exégesis en la que el ámbito competencial y las atribuciones de los sujetos intervinientes queden fijados con precisión ${ }^{4}$.

\section{El cementerio y los derechos sobre bienes cementeriales. Su concepción moderna derivada del Derecho administrativo}

Europa constituyó el escenario propicio para el surgimiento de los cementerios modernos, tal y como lo conocemos en la actualidad. La monarquía europea advierte las profundas afectaciones que a la salud genera la concentración de cadáveres en las ciudades ${ }^{5}$. Los cambios político-jurídicos en la Francia de finales del siglo XVII, permitieron el desarrollo del cementerio contemporáneo. La insalubridad de las ciudades, provocó que el debate del estado de los cementerios por la Corte del Parlamento francés en 1737. Así, mediante Edicto en 1763, se decide su traslado a las afueras de las ciudades ${ }^{6}$.

Otro tanto sucede en España, cuya situación de salubridad era semejante. En 1784, el rey Carlos III decide construir un cementerio para el Real Sitio de San Idelfonso, dotado de un Reglamento propio. Sin embargo, no fue hasta la promulgación de la Real Cédula del 3 de abril de 1787, que se materializó la prohibición de

\footnotetext{
3 Tolivar Alas, Leopoldo "Los servicios mortuorios locales: cementerios y servicios funerarios", en Muñoz, S. (Coord.) Tratado de Derecho Municipal, Volumen II, 2da Edición, Madrid, Civitas, 2003, pp. 1745-1748.

4 Rodríguez Blanco, Régimen Jurídico de cementerios y sepulturas, op. cit. p. 2.

5 Bertrand, Russell, “Estudio de los cementerios franceses contemporáneos. Los problemas de método", en Revista Trace, No. 58, diciembre 2010, pp. 71-81.

6 Ariés, Philip, El hombre ante la muerte, Madrid, Taurus Ediciones, 1984, p. 180.
} 
enterramientos intramuros ${ }^{7}$. Para la sociedad inglesa, la solución a la insalubridad provocada por los enterramientos parroquiales, fue la autorización de cementerios privados $^{8}$. Sin embargo, la situación requirió que en 1848 se sancionara Ley de Salud Pública, que sentó las bases de la salubridad pública e inició el proceso legislativo de los cementerios británicos.

Alemania atravesó esta situación de manera menos angustiosa. A raíz de la quiebra de los movimientos liberales de 1848, fueron sensibilizados por los problemas de las reformas sociales y políticas sucedidas. En este contexto, se forja la necesidad de la regulación de los nuevos cementerios extraurbanos ${ }^{9}$. Italia, siguiendo esta línea, pondera la Ley del 20 de marzo de 1865, denominada "Ley sobre la unificación administrativa del Reino". Con ella, se levantaron los cimientos del ordenamiento administrativo que perfiló la regulación administrativa de los cementerios ${ }^{10}$.

A partir del siglo $\mathrm{XIX}^{11}$, la mayoría de los antiguos cementerios parroquiales europeos se convirtieron en plazas, mercados o en instalaciones eclesiásticas. Surgió así la segunda generación de nuevos cementerios modernos que se caracterizarán por su aislamiento de la población. Sus concepciones y tipologías

7 González, A., El cementerio español de los siglos. XVIII y XIX, España, Archivo Español de Arte, No.171, 1970, pp. 289-320.

8 Keith-Lucas, B. y Richards, P. G. Historia del Régimen Local Inglés en el siglo XX. Colección "Administración y Ciudadano", trad. Joaquín Hernández, Madrid, Instituto de Estudios de Administración Local, 1980, p. 51.

9 El mayor exponente de estos escritores es relativamente tardío, su nombre es Lorenz van Stein al cual se debe un enorme Verwaltungslehre en 10 volúmenes que se comenzó a publicar en 1865. Giannini, Massimo Severo, Derecho Administrativo, trad. Luis Ortega, Vol. 1ro, Madrid, Ministerio de las Administraciones Públicas, 1991, pp. 61-62.

10 Alessi, Renato, Sistema Istituzionale di Diritto Amministrativo, Milano, Dott. A GiuffrèEditore, 1960, p. 20.

11 Esta etapa discurre desde el siglo XIX a nuestros días, y se caracteriza por la idea del Derecho reduciendo cada vez más la facultad discrecional del Estado. Sin embargo, a partir de 1914, se han intensificado la actividad del Estado, que podría hablarse de una nueva etapa, caracterizada por la intervención administrativa en la vida de las naciones. Monacelli, Gualterio, Elementos de Derecho Administrativo y Legislación Fiscal y Aduanera, 9na Edición, Buenos Aires, "El Ateneo", 1961, p. 11. 
fueron posteriormente expandidas al mundo entero, adoptando los diversos estilos modernos que sobre su constitución hoy existen $^{12}$.

\section{II.1 Entre la propiedad y la concesión: los derechos constituidos sobre sepultura}

Para las sociedades civilizadas, el derecho del hombre a que su cadáver reciba sepultura, y no quede expuesto a la intemperie o al abandono, constituye un atributo o prerrogativa inherente a la personalidad ${ }^{13}$. Al resultar el objeto de los cementerios, la inhumación de cadáveres humanos, las sepulturas devienen en su concreción. Desde las primeras culturas, la determinación de lugares de enterramientos alentó la constitución de derechos subjetivos sobre los sepulcros.

Las sepulturas españolas se concedían en el régimen de propiedad a perpetuidad, lo que las hacía susceptible de enajenación. Así estipulado en la ordenación de los cementerios municipales del siglo XIX, se establecía en diversos reglamentos de cementerios aprobados por los Ayuntamientos ${ }^{14}$. Esta condición, permitió su libre disposición, en consonancia a las regulaciones civiles. Los derechos otorgados a perpetuidad, en virtud del principio de confianza legítima, prevalecen con el respeto a las garantías reconocidas a favor del administrado. De esta forma, no cabe la aplicación retroactiva de las nuevas ordenanzas municipales que fijan un límite a la duración de las concesiones $^{15}$.

12 Cabarrou, N., “Cementerios parque: un espacio para la ilusión”, en Revista de Arquitectura SCA, Buenos Aires, No. 194, 1999, pp. 66-73.

13 Ortega García, Erick, El derecho a la sepultura y su contextualización normativa en el ordenamiento jurídico cubano. Tesis presentada en opción al grado académico de Máster en Derecho Constitucional y Administrativo, Universidad de Oriente, Cuba, 2016, pp. 35-42.

14 Rodríguez Blanco, Régimen Jurídico de cementerios y sepulturas, op. cit. pp. 103-108.

15 Ballesteros Moffa, Luis Ángel, “Los principios de irretroactividad y confianza legítima en el Derecho funerario: el régimen transitorio de los derechos de sepultura en la jurisprudencia", en Revista Española de Derecho Administrativo, Madrid, No. 129, 2006, pp. 173-197. 
Francia por su parte tuvo una similar concepción de los sepulcros. Entre el período de 1850 a 1870 y el de 1920 a 1950, se sitúa la edad de oro de los cementerios franceses. Estas etapas estuvieron marcadas por la aparición de tumbas fuera de lo común por el tamaño, los materiales, las esculturas y características del desarrollo de la propiedad de la concesión entre las clases medias ${ }^{16}$. Los cementerios franceses se constituyen ampliamente por fosas comunes y tumbas simples en provecho de las concesiones temporales y a perpetuidad ${ }^{17}$.

Otro sentido diametralmente opuesto tomó la regulación de los derechos sobre las sepulturas alemanas, al enmarcarlos en el ámbito privado. Desde finales del siglo XIX, la privatización de tareas públicas transforma al Derecho administrativo alemán. Su concepción se basa en la idea de que los particulares, con su iniciativa y sus recursos, pueden cumplir los cometidos públicos de mejor manera que las autoridades administrativas. El empresario privado tiene una responsabilidad de cumplimiento, en tanto el Estado solo de garantía. Así, las sepulturas se conceden por particulares, dentro del régimen privado de administración de cementerios ${ }^{18}$.

Las influencias europeas encontraron asidero en América con similar proyección. En Estados Unidos de América, durante la segunda mitad del siglo XIX, el Estado de Nueva York fue uno de los lugares mejor y más extensamente codificado. Como resultado, el Código Político de $1860^{19}$, constituye un manual de Derecho público administrativo, que especifica el desenvolvimiento del Estado. Es a partir de su artículo 1106 que ofrece una clara

\footnotetext{
16 Bertrand, Russell, "Oue de vertus.... Les épitaphes édifiantes des débuts du XIX e siècle", en Bertrand Russell, Anne C., y Jean-Noël P. , Les narrations de la mort, Aix-en-Provence, Publications de I'Université de Provence, 2005, pp. 241-255.

17 Bertrand, "Estudio de los cementerios franceses contemporáneos. Los problemas de método", op. cit.

18 Ibler, M., "Los nuevos retos y tendencias del Derecho administrativo en Alemania", en Revista IUSTA, Bogotá, No. 45, 2016, pp. 165-182.

19 New York Field Codes Series. Volume V. State of New York. The Lawbook Exchange, Ltd.Clark, New Jersey-Biblio.com, (Consulta: 2 de noviembre de 2018). Disponible en: https://www. biblio.com/bookstore/the-lawbook-exchangeltdclark\&usg=A0vVaw0T64rKbVIfZY7I_NMsAXH
} 
ordenación de los cementerios. De acuerdo a sus posturas, la adquisición de los cementerios debía realizarse a nombre del pueblo, siendo inenajenables, salvo resolución de autoridad comunal ${ }^{20}$.

Más controversial ha sido el tratamiento de los sepulcros en Argentina. Importantes autores como Barraquero, sostuvo que el sepulcro constituye un bien de naturaleza civil. Para ello, se fundamentan en el Decreto argentino del 3 de septiembre de 1823, en el que se enuncian términos como venta y compra de sepulturas. Ello significa que se trataba de bienes privados, criterio que también seguía la Ley Orgánica de la Municipalidad de Buenos Aires, No. 1260. En efecto, estos términos, en unión a otros como propiedad de las sepulturas, venta de nichos, panteones particulares, comprador de terreno para sepulcro, se empleaban con otras expresiones que contradecían a aquéllas ${ }^{21}$.

De la regulación administrativa de los camposantos modernos a partir del siglo XVIII, se evidencia que, a pesar de ser doctrina aceptada su sometimiento al servicio público, los derechos que sobre sus bienes se constituyeron no siempre guardaron esta misma esencia. Ello provocó su aprovechamiento individual desentendido de la unidad inmobiliaria. Precisamente, la sepultura deviene en la expresión concreta y materializada del derecho de uso público emergente, asentado sobre la dependencia demanial que resulta el cementerio ${ }^{22}$.

\section{Los cementerios públicos como sujetos de derechos. Su naturaleza jurídica ¿pública o privada?}

A partir de la secularización de los cementerios públicos, comienza una seria confrontación doctrinal en cuanto a su

\footnotetext{
20 Miguens, A. M. "Se pulcro", XXXII Jornada Notarial Argentina, Buenos Aires, 24-26 de agosto de 2016.

21 Barraquero, Carette, Attwell, Ocantos, Requena, Diccionario de Legislación Nacional y Provincial, Tomo II, Buenos Aires, Tipográfica Editora Argentina, 1912, pp. 295, 298 y 300.

22 Marienhoff, Miguel S. Tratado de Derecho Administrativo, Tomo V, Buenos Aires, Depalma, 1960, pp. 252-271.
} 
condición jurídica. Al efecto, se distinguen tres grupos que defienden posiciones doctrinarias opuestas. El primero, les atribuye carácter de bienes privados del Estado ${ }^{23}$; el segundo, los considera bienes integrantes del dominio público ${ }^{24}$ y el último plantea una teoría ecléctica en la que los cementerios sólo en parte son bienes del dominio público, pues sus nichos y sepulcros, constituyen bienes privados del municipio y los concesionarios ${ }^{25}$.

El fundamento privado de los cementerios se sustenta en que, al resultar éstos fuentes de recursos para las comunas, pueden otorgarse concesiones onerosas, que permitan al Estado recibir un beneficio económico. Tal análisis parte de la existencia de cementerios privados, sobre los que se ejerce la afectación al servicio de inhumaciones y el poder de policía. Por lo que estas potestades no resultan incompatibles con la propiedad privada ${ }^{26}$.

Para Guicciardi, el carácter privado de los cementerios se debe a que la actividad del Estado respecto de los cementerios

23 Batbie, A. P. , Traité théorique et pratique de Droit Public et Administratif, Tome 5, Paris, L. Larose et Forcel Libraires-Editeurs, 1888, p. 319; Ducrocq, Th., Cours de Droit Administratif, Tome 6, No. 2305, Paris, Ancienne Librairie Thorin et Fils. A. Fontemoings, Éditeurs, 1900 , pp. 270-272; Journè, Maurice, Précis de Droit Administratif, Paris, Librairie de la Société du Recueil Sirey, 1925, p. 329; Guicciardi, Enrico, II Demanio, Milano, CEDAM, 1934, pp. 153-154.

24 Proudhon, Pierre-Joseph, Traité du domaine public, ou de la distinction des biens considérés principalement par rapport au domaine public, Tome Premier, Dijon, Ed. Chez Victor Lagier, Libraire-Éditeur, 1833, pp. 460-462; Mayer, Otto, El derecho administrativo alemán, Tomo III, Buenos Aires, Depalma, 1950, pp. 121-122 y 236; Hauriou, Maurice, Précis de droit administratif, Paris, Ed. Recueil Sirey, 1927, p. 826; Fernández de Velasco, Recaredo, Naturaleza jurídica de cementerios y sepulturas: historia y problemas jurídicos, Madrid, Revista de derecho privado, 1935, pp. 203-205; Laubadère, André de, “Les concessions dans les cimetières", en Revue du droit public et de la science politique, Paris, Dalloz, 1936, pp. 612620; Jansse, Lucien, Les traits principaux du régime des biens du domaine public, Paris, Dalloz, 1938, pp. 125-126.

25 Salvat, Raymundo, Tratado de Derecho Civil Argentino (Derechos Reales), Tomo 1, No. 1436 , Buenos Aires, Tipográfica Editora Argentina, 1923, p. 751. Pérez Gálvez, Juan Francisco, El sistema funerario en el Derecho español, Pamplona, Aranzadi, 1997, pp. 335-348.

26 Ducrocq, Cours de Droit Administratif, Tome 6, op. cit. p. 271; Batbie, Traité théorique et pratique de Droit Public et Administratif, op. cit. p. 319. 
no es exclusiva de él, pues también existen cementerios particulares. Pero como la exclusividad de las respectivas funciones del Estado, es uno de los requisitos que deben concurrir para que la cosa pueda considerarse demanial, debe negarse esta condición a los cementerios. Por su parte, Barraquero le atribuyó este carácter, basado en las leyes dictadas al respecto, que disponían la venta de las parcelas para construir sepulcros, al considerarlas una desafectación del respectivo bien público ${ }^{27}$.

En los aspectos referidos, debe valorarse que los bienes demaniales no requieren necesariamente la improductividad, o que las concesiones de uso sean gratuitas. Además, en el caso de los cementerios privados, no puede hablarse de dominio público, al no concurrir uno de sus elementos indispensables: el elemento subjetivo. A ello se suma que la condición del cementerio ha de encontrarse en sí mismo. No es público o privado porque pertenezca o uno u otro sujeto, pues la realidad jurídica positiva no distingue, refiriendo simplemente, cementerio. Por eso, el poder de policía se manifiesta sobre toda clase de actividades, ya sean públicas o privadas ${ }^{28}$.

La teoría ecléctica, que hace distinción entre el régimen de dominio público sobre el cementerio, y de dominio privado sobre los sepulcros, dio lugar a un considerable número de corrientes doctrinales que intentaron justificar su naturaleza jurídica. Algunos autores pretendieron resolver esta cuestión sosteniendo que los sepulcros constituyen una propiedad sui generis $^{29}$, criterio que siguieron algunos tribunales. Otros expositores consideraron al derecho de sepulcro como un contrato

\footnotetext{
27 Barraquero, referenciado en Marienhoff, Tratado de Derecho Administrativo, Tomo V, op. cit. pp. 255-256.

28 Villegas Basavilbaso, B. Derecho...Tomo IV ...ob.cit., p. 403.

29 Esta doctrina plantea la diferenciación entre el derecho de acceso al servicio (cementerio), y el uso privativo sobre el bien de dominio público (sepultura), por lo que la naturaleza de las sepulturas privadas en los cementerios municipales no consisten en derechos reales administrativos, sino en una propiedad sui generis. Salvat, Tratado de Derecho Civil Argentino (Derechos Reales), Tomo 1, op. cit. p. 751. Pérez Gálvez, El sistema funerario en el Derecho español, op. cit. pp. 335-348.
} 
innominado celebrado entre el Estado y el particular. Por último, se suma la opinión que igualó al sepulcro con un bien de derecho civil $^{30}$, estableciendo una propiedad común sobre el sepulcro ${ }^{31}$.

Se impone entonces la doctrina del dominio público. El cementerio, como parte del dominio público, aparte de consentir su uso -común o especial- por los administrados, presta el servicio público de inhumaciones. Sobre la base de un bien demanial, cuyo uso tienen los administrados, existe, además, prestación de un servicio público. Por tanto, es el cementerio un servicio público, en tanto que la sepultura se traduce en el uso de ese servicio $^{32}$.

\section{Límites y contenido de los derechos reconocidos en los cementerios públicos. Otros derechos en colisión}

La esencia demanial de los cementerios públicos, atribuye igual naturaleza jurídica a las sepulturas incorporadas a ellos. Tal situación pondera un servicio público destinado a su uso privativo, que deviene en el acto jurídico en cuyo mérito los particulares pueden adquirir derechos. Así, se garantiza que la sepultura sea únicamente utilizada de acuerdo a su fin, por personas con facultad para ello. Su materialización se lleva a cabo a través de los medios que al efecto establezca o reconozca la normativa vigente en el lugar ${ }^{33}$. En tal sentido pueden ser, el permiso de uso $^{34}$ aplicado por la Administración para que

\footnotetext{
30 Igual criterio sigue la Corte Suprema de Justicia de la Nación argentina. Citada en Marienhoff, Tratado de Derecho Administrativo, Tomo V, op. cit. p. 260.

31 Bielsa, Derecho administrativo, Tomo III, op. cit. p. 444.

32 Fernández de Velasco, Naturaleza jurídica de cementerios y sepulturas: historia y problemas jurídicos, op. cit. p. 248.

33 Fernández de Velasco es claro cuando reconoce los usos privativos temporales y a perpetuidad, como medios de expresión de derechos sobre sepulturas, criterio al que se afilia la investigación. Fernández de Velasco, Naturaleza jurídica de cementerios y sepulturas: historia y problemas jurídicos, op. cit. pp. 210-211.

34 Garrido Falla, Fernando, Tratado de Derecho Administrativo, Volumen II (Parte General: Conclusión), 7ma edición, Madrid, Centro de Estudios Constitucionales, 1986, p. 471.
} 
los usuarios aprovechen y usen los cementerios; y la concesión de uso $^{35}$ para actividades de importancia jurídica-económicasocial $^{36}$.

Cabe entonces delimitar los tipos de sepulturas en los que serán utilizados uno u otro medio de uso. Por un lado, el uso de fosas u osarios comunes y nichos, será autorizado a través de un permiso. En cambio, el uso de la tierra como sepultura y sepulcros, entendidos como bóvedas, panteones, mausoleos, serán autorizados mediante un acto concesional. En este entorno, baste significar que la concesión, a diferencia del permiso, no es el otorgamiento de un derecho precario. Al contrario, se otorga un verdadero derecho subjetivo para su concesionario, conformándose como un derecho real administrativo ${ }^{37}$.

El derecho de los permisionarios, se enmarca en uso exclusivo y excluyente. Ello conlleva a que desde el momento de su otorgamiento, para la custodia, guarda y depósito de cadáveres, se excluye cualquier otro fin para el cual pudiera destinarse. No obstante, bajo la nota de precariedad, la Administración se reserva el derecho de establecer un término de duración, y extinguirlo unilateralmente. Esta situación justifica que, para la utilización de fosas comunes y nichos, es la Administración quien asume su edificación y emplazamiento. Por tanto, a pesar de que su uso pueda disponerse de forma gratuita u onerosa, este derecho no genera la posibilidad de trasmisión a terceros ${ }^{38}$.

Por otro lado, el derecho de los concesionarios implica, además del descrito uso exclusivo y excluyente, la atribución de

\footnotetext{
35 Matilla Correa, Andry, Fundamentos del régimen jurídico de las concesiones administrativas. Una visión cubana. Tesis en opción al grado científico de Doctor en Ciencias Jurídicas. Universidad de La Habana, 2005, p. 36

36 Fernández de Velasco, Naturaleza jurídica de cementerios y sepulturas: historia y problemas jurídicos, op. cit. p. 162.

37 Mayer, El derecho administrativo alemán, Tomo III, op. cit. p. 248; González Pérez, Jesús, Los derechos reales administrativos, Madrid, Civitas, S.A., 1975, p. 106.

38 Fernández de Velasco, Naturaleza jurídica de cementerios y sepulturas: historia y problemas jurídicos, op. cit. p. 210.
} 
levantar la construcción o monumento funerario. Esta facultad deviene en un derecho inherente al uso mismo de la concesión. En estos casos, debe conllevar la posibilidad de construir los elementos indispensables para la consecución del fin para el cual se otorgó. Además, genera la posibilidad de su trasmisión a terceros por acto inter vivos o mortis causa. Esta trasmisión se puede ejecutar, siempre que la concesión no lo prohíba y se respeten sus condiciones, o esté permitido según los reglamentos municipales. Pueden constituirse a título gratuito u oneroso, cuando se pacta algún precio, éste será un simple canon, que no debe confundirse con impuesto o tas ${ }^{39}$.

Otra cuestión que resalta, es el otorgamiento de concesiones de forma temporal o perpetua. Al respecto, existen dos corrientes, que si bien coinciden en la temporalidad de las concesiones, sus opiniones se bifurcan en cuanto a su perpetuidad ${ }^{40}$. El primer grupo plantea que la perpetuidad del derecho de uso equivale a una enajenación de la cosa respectiva, chocando con el carácter de los bienes públicos ${ }^{41}$. La existencia de un plazo cierto prorrogable, al decir de Parada ${ }^{42}$, constituye un requisito estructural de la concesión, que asegura la continuidad de la prestación del servicio, y garantiza los derechos del concesionario.

Los seguidores de esta corriente se basan en la significación del plazo para el cumplimiento y extinción de la concesión. Este

\footnotetext{
39 Marienhoff, Tratado de Derecho Administrativo, Tomo V, op. cit. pp. 187-189.

40 Existe una corriente doctrinaria que excluye a las sepulturas del régimen concesional. En ella se enfatiza que la concepción de la sepultura se resuelve con el servicio público. Por lo que, al considerarla como un servicio, su naturaleza de cosa sagrada, no le permite ser objeto de contrato, ni de legado, ni susceptible de prescripción, embargo o hipoteca. Por tanto, su otorgamiento constituye una prestación singular de un servicio público que se identifica con la utilización excluyente del bien. Zanobini, Curso de Derecho Administrativo, Volumen I, op. cit. p. 106; Alessi, Renato, Instituciones de Derecho Administrativo, Tomo II, Barcelona, Bosch, 1970, p. 411. Al alejarse de la concepción de uso privativo, a este criterio no se acoge el presente artículo.

41 Opinión sostenida por Dalmacio Vélez Sarsfield, seguida por varios escritores patrios. Marienhoff, Tratado de Derecho Administrativo, Tomo V, op. cit. p. 184.

42 Parada Vázquez, José Ramón, Derecho Administrativo, Tomo I, Parte General, $15^{a}$ Edición, Madrid, Marcial Pons, 2004, p. 347.
} 
puede concretarse con el señalamiento de un límite temporal de ejercicio de los derechos y facultades que la concesión otorga al concesionario. Su término es no sólo cierto, sino fijo o determinado (dies certus an et quando). Así mismo, en el aspecto jurídico constituye una garantía del respeto de la Administración hacia el ejercicio de esos derechos y facultades ${ }^{43}$.

Visto así, la temporalidad deviene en principio estructural en la relación concesional. Sin embargo, encuentra una excepción ante la posibilidad de constituirse sin un plazo o término fijado ${ }^{44}$. En tales casos, se configuran las concepciones perpetuas de sepulturas, acogidas por el segundo grupo de tratadistas, que reconocen la validez jurídica de la perpetuidad en las concesiones de uso ${ }^{45}$.

La concesión de uso otorgada a perpetuidad, es compatible con el régimen del dominio público. Esta aseveración se sustenta en que tal condición provee la seguridad jurídica que garantiza el bienestar y tranquilidad individuales. Al resultar constitutivas de un derecho de uso acorde a su destino, no son traslativas de dominio. Su situación jurídica se equipara al tratamiento de las concesiones temporarias susceptibles a renovaciones sucesivas. Además, a pesar de su condición, el Estado puede imponer sobre ellas las modificaciones que se deriven de nuevas necesidades sociales. Por último, la perpetuidad no impide la revocación de la concesión, cuando razones de interés público así lo requieran ${ }^{46}$.

\footnotetext{
43 Villar Palasí, José Luis, Concesiones administrativas, Tomo IV, Barcelona, N.E.J. Seix, 1952, p. 756; Albi, Fernando, Tratado de los modos de gestión de las Corporaciones Locales, Madrid, Aguilar, 1960, p. 650; López Pellicer y Sánchez Díaz, La concesión administrativa en la esfera local, op. cit. pp. 189-191.

44 Matilla Correa, Fundamentos del régimen jurídico de las concesiones administrativas. Una visión cubana, op. cit. p. 125.

45 Arbus, Pacelli, Bibiloni, Lafaille. Así lo refiere Fernández de Velasco, Naturaleza jurídica de cementerios y sepulturas: historia y problemas jurídicos, op. cit. pp. 243-244.

46 Fernández de Velasco, Naturaleza jurídica de cementerios y sepulturas: historia y problemas jurídicos, op. cit. pp. 243-244.
} 
Desde estas opiniones debe entenderse que, en el régimen concesional de las sepulturas, la renovación tutela la voluntad de los familiares, de hacer reposar los restos de sus seres queridos en un determinado lugar. Con ella se garantizaría a su vez, la transmisibilidad del derecho funerario y el uso privativo de construcciones como panteones y mausoleos. Para el cementerio, como bien de dominio público, la renovación de una concesión una vez expirado el plazo de duración, contribuye al cumplimiento de su finalidad concreta. Ésta debe tener lugar, siempre que no existieran razones objetivas de interés público que lo impidan, en cuyo caso concreto, la Administración tendría que acreditar ${ }^{47}$.

Así, la posesión desarrollada tanto por los permisionarios, como por los concesionarios, no puede ser civil, al carecerse de la intensión de apropiarse de la cosa. Tampoco puede poseerse en otro concepto que en el de tenedor que la conserva o disfruta, por encontrarse el dominio en otra persona ${ }^{48}$. No obstante, se les reconoce el derecho a promover acciones posesorias contra terceros, respecto al uso de la cosa objeto del permiso o concesión. Ello se debe a que tales permisionarios y concesionarios, con relación a terceros, poseen la quasi possessio iuris del bien.

En el contenido de ambos medios de uso privativo se enmarcan las servidumbres administrativas que en su utilización se dispongan. Sólo se requiere para su imposición, que sean compatibles con el fin que motiva la afectación de la cosa. De igual forma, se ejercen las potestades administrativas que protegen el pleno dominio de la Administración concedente, en armónica relación de intereses púbicos y privados.

\section{Conclusiones}

De manera general, la existencia de cementerios y lugares enterramientos data desde la antigüedad. Durante el cristianismo,

\footnotetext{
47 Rodríguez Blanco, Régimen Jurídico de cementerios y sepulturas, op. cit. p. 109.

48 Fernández de Velasco, Naturaleza jurídica de cementerios y sepulturas: historia y problemas jurídicos, op. cit. pp. 211-212.
} 
los romanos variaron las costumbres funerarias, al utilizar fosas comunes llamadas catacumbas. La expansión del cristianismo en la Edad Media, resultó en la construcción de iglesias y alrededor de ellas los cementerios. En estos fue sepultada la gente común, mientras que el clérigo y la nobleza se ubicaban en el interior de las iglesias. A partir del siglo XVIII esta costumbre medieval fue criticada, por los malos olores que originaron focos de enfermedades y la saturación de estos espacios. Así, a finales del siglo XVIII se establecieron los cementerios extraurbanos modernos.

Los cementerios antiguos se mantuvieron bajo un manto religioso y mágico, concebidos como cosa fuera del comercio, sobre ellos no podían constituirse derechos privados. Sin embargo, la época medieval concibió el otorgamiento de derechos de propiedad a perpetuidad sobre espacios de enterramiento. El siglo XX trajo consigo fuertes corrientes doctrinales española, francesa, alemana e italiana, que enmarcaban a los cementerios y sepulturas en el ámbito público o privado del Derecho. Estas influencias impactaron en América concibiéndose de manera similar a la doctrina europea. No obstante, cada cultura ha aplicado sus propios rituales funerarios y sus formas específicas de concebir los enterramientos.

Mucho se ha debatido sobre la naturaleza jurídica de los cementerios; pero ha sido la doctrina del dominio público la que ha primado en la concepción normativa de los cementerios. Por ello, aunque subsisten doctrinas que enmarcan a los derechos sobre sepulturas dentro de la propiedad, se ha impuesto el régimen demanial, cuyos medios de uso privativo resultan el permiso de uso y la concesión de uso (temporal o perpetua). En ambos medios se enmarcan, tanto servidumbres administrativas, como las potestades administrativas protectores del dominio administrativo, moldeando así la amplitud y contenido de estos derechos.

\section{Bibliografía}

Albi, Fernando (1960). Tratado de los modos de gestión de las Corporaciones Locales, Madrid, Aguila. 
Alessi, Renato (1970). Instituciones de Derecho Administrativo, Tomo II, Barcelona, Bosch.

Alessi, Renato (1960). Sistema Istituzionale di Diritto Amministrativo, Milano, Dott. A Giuffrè-Editore.

Ariés, Philip (1984). El hombre ante la muerte, Madrid, Taurus Ediciones.

Ballesteros Moffa, Luis Ángel (2006). "Los principios de irretroactividad y confianza legítima en el Derecho funerario: el régimen transitorio de los derechos de sepultura en la jurisprudencia", en Revista Española de Derecho Administrativo, Madrid, $\mathrm{N}^{\circ} 129$, pp. 173-197.

Barraquero, Carette, Attwell, Ocantos, Requena (1912). Diccionario de Legislación Nacional y Provincial, Tomo II, Buenos Aires, Tipográfica Editora Argentina.

Batbie, A. P. (1888). Traité théorique et pratique de Droit Public et Administratif, Tome 5, Paris, L. Larose et Forcel LibrairesEditeurs.

Bertrand, Russell (2005). "Que de vertus.... Les épitaphes édifiantes des débuts du XIX e siècle”, en Bertrand Russell, Anne C., y Jean-Noël P. , Les narrations de la mort, Aix-en-Provence, Publications de l'Université de Provence, pp. 241-255.

Bertrand, Russell (2010). "Estudio de los cementerios franceses contemporáneos. Los problemas de método", en Revista Trace, No. 58, diciembre, pp. 71-81.

Bielsa, Rafael (1956). Derecho administrativo, Tomo III, 5ta Edición, Buenos Aires, Depalma.

Bullrich, Rodolfo (1999). Curso de Derecho Administrativo, Tomo II, Buenos Aires, Abeledo Perrot S.A, 1932.

Caetano, Marcello (1970). Manual de Direito Administrativo, Tomo I, Rio de Janeiro, Companhia Editora Forense.

Ducrocq, Th. (1900). Cours de Droit Administratif, Tome 6, No. 2305, Paris, Ancienne Librairie Thorin et Fils. A. Fontemoings, Éditeurs.

Escovar, A., (2009). "Vida, resurrección y muerte en la arquitectura funeraria", en AAVV, Las ciudades y los muertos. Cementerios de América Latina, (Consulta: 24 de abril de 2016). 
Disponible en: http://www.museodebogota.gov.co/descargas/ publicaciones/pdf /Vida.pdf

Fernández de Velasco, Recaredo (1935). Naturaleza jurídica de cementerios y sepulturas: historia y problemas jurídicos, Madrid, Revista de derecho privado.

García de Enterría Eduardo y Fernández, T.R. (1997). Curso de Derecho Administrativo, Tomo I, Octava Edición, Madrid, Civitas.

Garrido Falla, Fernando (1986). Tratado de Derecho Administrativo, Volumen II (Parte General: Conclusión), 7ma edición, Madrid, Centro de Estudios Constitucionales.

Giannini, Massimo Severo (1991). Derecho Administrativo, trad. Luis Ortega, Vol. 1ro, Madrid, Ministerio de las Administraciones Públicas.

González, A. (1970). El cementerio español de los siglos. XVIII y XIX, España, Archivo Español de Arte, No.171,.

González Pérez, Jesús (1934). Los derechos reales administrativos, Madrid, Civitas, S.A., 1975.

Hauriou, Maurice (1927). Précis de droit administratif, Paris, Ed. Recueil Sirey.

Ibler, M. (2016). "Los nuevos retos y tendencias del Derecho administrativo en Alemania", en Revista IUSTA, Bogotá, No. 45 pp. 165-182.

Jansse, Lucien (1938). Les traits principaux du régime des biens du domaine public, Paris, Dalloz,.

Journè, Maurice (1925). Précis de Droit Administratif, Paris, Librairie de la Société du Recueil Sirey,.

Keith-Lucas, B. y Richards, P. G (1980). Historia del Régimen Local Inglés en el siglo $X X$. Colección "Administración y Ciudadano", trad. Joaquín Hernández, Madrid, Instituto de Estudios de Administración Local.

Lafaille, Héctor (1944). Tratado de los Derechos Reales, Tomo II, No. 1016, Buenos Aires, Tipográfica Editora Argentina.

Laubadère, André de, (1936) "Les concessions dans les cimetières", en Revue du droit public et de la science politique, Paris, Dalloz, pp. 612- 620. 
López Pellicer José A., y Sánchez Díaz, José L (1976). La concesión administrativa en la esfera local. Servicios, obras y dominio público, Madrid, Instituto de Estudios de Administración Local. Marienhoff, Miguel S. (1960). Tratado de Derecho Administrativo, Tomo $V$ "Noción de dominio público. Clasificación. Afectación $y$ desafectación. Elementos que integran la noción de dominialidad. Régimen y caracteres jurídicos. Tutela o protección. Uso del dominio público. Permiso. Concesión. Uso adquirido por prescripción", Buenos Aires, Depalma.

Matilla Correa, Andry (2005). Fundamentos del régimen jurídico de las concesiones administrativas. Una visión cubana. Tesis en opción al grado científico de Doctor en Ciencias Jurídicas. Universidad de La Habana,.

Mayer, Otto, El derecho administrativo alemán, Tomo III, Buenos Aires, Depalma, 1950.

Miguens, Alberto M. "Se pulcro", XXXII Jornada Notarial Argentina, Buenos Aires, 24-26 de agosto de 2016.

Monacelli, Gualterio (1961). Elementos de Derecho Administrativo y Legislación Fiscal y Aduanera, 9na Edición, Buenos Aires, "El Ateneo".

New York Field Codes Series. Volume V. State of New York. The Lawbook Exchange, Ltd.- Clark, New Jersey-Biblio.com, (Consulta: 2 de noviembre de 2018). Disponible en: https:// www.biblio.com/bookstore/the-lawbook-exchange-ltdclark\&usg=AOvVaw0T64rK bVlf-ZY71_NMsAXH

Ortega García, Erick (2016). El derecho a la sepultura y su contextualización normativa en el ordenamiento jurídico cubano. Tesis presentada en opción al grado académico de Máster en Derecho Constitucional y Administrativo, Universidad de Oriente, Cuba,.

Parada Vázquez, José Ramón (2004). Derecho Administrativo, Tomo I, Parte General, $15^{\text {a }}$ Edición, Madrid, Marcial Pons,.

Pérez Gálvez, Juan Francisco (1997). El sistema funerario en el Derecho español, Pamplona, Aranzadi,.

Proudhon, Pierre-Joseph (1833). Traité du domaine public, ou de la distinction des biens considérés principalement par rapport au domaine public, Tome Premier, Dijon, Ed. Chez Victor Lagier, Libraire-Éditeur,. 
Rodríguez Blanco, Miguel (2015). Régimen Jurídico de cementerios y sepulturas, Granada, Comares S. L..

Rolland, Louis (1938). Précis de droit administratif, 7ème Édition, Paris, Dalloz,.

Salvat, Raymundo (1923). Tratado de Derecho Civil Argentino (Derechos Reales), Tomo 1, No. 1436, Buenos Aires, Tipográfica Editora Argentina,.

Tolivar Alas, Leopoldo (2003). "Los servicios mortuorios locales: cementerios y servicios funerarios", en Muñoz, S. (Coord.) Tratado de Derecho Municipal, Volumen II, 2da Edición, Madrid, Civitas, pp. 1745-1748.

Villar Palasí, José Luis (1952). Concesiones administrativas, Tomo IV, Barcelona, N.E.J. Seix.

Villegas Basavilbaso, Benjamín (1952). Derecho Administrativo, Tomo IV, Instituciones fundamentales (segunda parte) - Dominio público, Buenos Aires, Tipográfica Editora Argentina.

Waline, Marcel (1936). Élémentaire de Droit Administratif, Paris, Librairie du Recueil Sirey,.

Zanobini, Guido (1954). Curso de Derecho Administrativo, Volumen I, Parte General, Buenos Aires, Ayadú. 